\title{
Discurso, argumentação e ensino: elementos para uma abordagem transdisciplinar
}

\author{
Discourse, argumentation and teaching: elements for a transdisciplinarity approach \\ Marcos Bispo dos Santos* \\ Universidade do Estado da Babia, Santo Alagoinhas, Bahia, Brasil
}

\begin{abstract}
Resumo: Neste ensaio, tem-se como objetivo apresentar elementos necessários para uma abordagem transdisciplinar de estudo da argumentação, tendo em vista sua aplicação ao processo de ensinoaprendizagem de leitura e produção de textos argumentativos. Partindo do pressuposto de que as perspectivas monodisciplinares da linguística se mostram limitadas para abordar o tema da argumentação em sua complexidade, devido a seu compromisso com a produção de conhecimentos de base em que prevalece a fragmentação do saber, postula-se que tal tarefa só poderia ser levada a termo por uma linguística concebida como ciência aplicada crítica. Assim, defende-se que a estrutura formal da argumentação deve ser depreendida das práticas de linguagem que engendram os gêneros textuais imbuídos, direta ou indiretamente, do objetivo de persuadir. Para isso, propõem-se dois caminhos. O primeiro deles consiste na construção de um aparato teórico-metodológico, a partir da apropriação de construtos teóricos da retórica antiga, da nova retórica e de teorias linguísticas como a pragmática, a linguística textual, a semântica argumentativa, teorias dos gêneros textuais, a análise de discurso, teorias enunciativas, a análise da conversação, da sociologia, dos estudos culturais, da filosofia, da filosofia da linguagem e outras, de acordo com os objetivos do processo de ensino-aprendizagem. $\mathrm{O}$ segundo caminho consiste na construção de um dispositivo teórico metodológico capaz de fundamentar práticas de análise e produção de textos argumentativos, concebidos como objetos de extrema complexidade.
\end{abstract}

Palavras-chave: Discurso. Ensino de argumentação. Transdisciplinaridade. Linguística Aplicada.

\begin{abstract}
In this essay, we aim to present the necessary elements for a transdisciplinary approach of the study of argumentation in order to apply it to the teaching-learning process of argumentative texts reading and production. Assuming that mono-disciplinary perspectives in Linguistics are limited to deal with the complexity argumentation, due to its commitment to the production of basic knowledge in which prevails knowledge fragmentation, it is postulated that such a task could only be successfully carried out if Linguistics is conceived as a critical applied science. Thus, it is argued that the formal structure of argumentation must be deduced from the language practices that engender the textual genres imbued, directly or indirectly, with the aim of persuading. Two paths are suggested. The first one involves the construction of a theoretical and methodological apparatus, from the appropriation of theoretical constructs of ancient rhetoric, the new rhetoric and linguistic theories as pragmatic, textual linguistics, argumentative semantics, theories of genres, analysis speech, enunciation theories, conversation analysis, sociology, cultural studies, philosophy, language philosophy and others, according to the objectives of the teaching-learning process. The second path consists in the construction of a theoretical methodological device capable of substantiating practices of analysis and production of argumentative texts that are conceived as extremely complex objects.
\end{abstract}

Keywords: Discourse. Teaching Argumentation. Transdisciplinarity. Applied Linguistics

\section{INTRODUÇÃO}

O desenvolvimento das habilidades de argumentar constitui, ao mesmo tempo, uma das maiores necessidades e uma das maiores limitações do ensino de

\footnotetext{
* Professor Adjunto do Departamento de Educação, Colegiado de Letras - Língua Portuguesa e Literaturas, Campus II, e do Metrado Profissional em Letras, Campus V, da Universidade do Estado da Bahia. Email: mabispo@uneb.br.
} 
linguagem no Brasil. A prática de produção de textos argumentativos, no Ensino Médio, tem-se restringido à elaboração dos conhecidos textos dissertativos, sobretudo por ser esse o gênero exigido nos exames de acesso aos cursos da educação de nível superior. Nesse contexto, a prática escolar opõe a dissertação às outras duas formas composicionais tidas como não argumentativas: a narração e a descrição. Essa divisão estanque e redutora apresenta, de imediato, três inconvenientes que, mesmo reconhecidos hoje, no momento em que diversas teorias investigam múltiplos aspectos que envolvem o funcionamento da linguagem, ainda compromete a prática de um ensino de argumentação capaz de fornecer aos estudantes subsídios cognitivos e discursivos para o pleno exercício da cidadania no mundo contemporâneo.

O primeiro inconveniente a ser destacado é a descontextualização das práticas escolares com aquilo que Habermas chamou de mundo da vida. Nenhuma prática social externa ao ambiente escolar vai exigir do estudante a produção de dissertações, narrações e descrições, no sentido estrito dos termos. Ao contrário, exigirão textos concretos, produzidos para circular em situações sociais concretas.

O segundo inconveniente está relacionado à concepção de argumentação subjacente às práticas de professores e estudantes. O que é argumentar? Uma resposta quase consensual seria que argumentar é selecionar argumentos adequados para se defender uma opinião. Mas o que é um argumento? Quais critérios são utilizados para se classificar um argumento como adequado? Como se formula uma opinião? Ou melhor: de onde uma opinião retira a legitimidade que a torna passível de defesa ou de aceitação? Por que uma opinião precisa ser defendida? Não lhe bastaria simplesmente ser enunciada?

$O$ terceiro refere-se à concepção de texto argumentativo que ainda predomina nos espaços escolares. O que impede que a narração e a descrição sejam utilizadas com finalidades argumentativas? Se essas três categorias permitem agrupar os vários textos que circulam socialmente, como classificar o conto ou o romance, por exemplo, já que tais gêneros podem apresentar tanto narração, como descrição ou argumentação? Como classificar uma reportagem, uma letra de música, um ensaio etc.?

Um passo em direção ao enfrentamento desse último inconveniente causado pela concepção redutora e estanque das formas composicionais foi dado com a teorização sobre os gêneros discursivos/textuais. Partindo do pressuposto de que a cada enunciação produzimos gêneros do discurso, Bakhtin (2003) os definiu como formas relativamente estáveis e típicas de construção de enunciados. Dessa forma, ampliou a classificação clássica de gêneros literários e gêneros retóricos, passando a considerar todo e qualquer enunciado como gênero discursivo. Postulou ainda que esses enunciados refletem as condições específicas e as finalidades de cada campo da atividade humana por meio de seu conteúdo temático, pelo estilo da linguagem e por sua construção composicional.

A partir dos trabalhos de Bakhtin, cresceu o interesse de linguistas e estudiosos pelos gêneros discursivos/textuais. Meurer et. al. (2005) publicaram um volume em que as diversas abordagens foram classificadas em três grupos: i) abordagens sócio-semióticas, incluindo concepções de Ruqayia Hasan, da perspectiva teológica de J. R. Martin, da linguística crítica de R. Fowler, da 
perspectiva discursivo-semiótica de G. Kress e da análise crítica de Fairclough; ii) abordagens sócio-retóricas, apresentando a proposta sócio retórica de J. M. Swales e a concepção de gênero como ação social, de C. R. Miller e C. Bazerman; iii) abordagens sócio-discursivas, abrangendo os gêneros na perspectiva dialógica de Bakhtin, a noção de sequência textual na análise pragmático-textual de Jean-Michel Adam, a perspectiva interacionista sociodiscursivas de Bronckart e o gênero como componente do arquivo, de Dominique Maingueneau. Todas essas abordagens, no entanto, deixam de fora de seu escopo:

a) uma teoria acerca da natureza da argumentação e das técnicas argumentativas;

b) uma estilística dos gêneros argumentativos;

c) uma teorização ampla e articuladora da relação discurso subjetividade - argumentação - texto.

No âmbito da linguística moderna, a argumentação tem sido estudada predominantemente sob o enfoque da argumentação na língua (ANSCOMBRE e DUCROT, 1997), que também está na base da teoria das sequências textuais argumentativas (ADAM, 2008) e tipo textual (MARCUSCHI, 2002). Conforme postulam Anscombre e Ducrot, um locutor faz uma argumentação quando apresenta um enunciado $\mathrm{E}_{1}$ (ou um conjunto de enunciados) como destinados a fazer admitir um outro (ou um conjunto de outros) $\mathrm{E}_{2}$. Para que isso seja possível, a estrutura linguística de $\mathrm{E}_{1}$ deve satisfazer a certas condições para que seja apto a constituir, no discurso, um argumento para $\mathrm{E}_{2}$. Embora estejamos de acordo com o princípio que subjaz a tal definição - a argumentação, de fato, só existe quando se pretende fazer aceitar uma tese -, parece muito redutora a ideia de que as condições que legitimam os enunciados argumentativos sejam regidas por coerções exercidas pela estrutura linguística.

Koch (2004) admite faltarem obras que, partindo de um estudo teórico sobre a argumentatividade na língua, busquem uma aplicação desse estudo à análise e, consequentemente, à leitura e produção de textos. Entretanto, a autora concentra suas análises nas marcas linguísticas da argumentação, com foco especial nos chamados operadores lógico-discursivos. Logo, essas duas perspectivas de estudo da argumentação também deixam de fora de seu escopo os aspectos relacionados à argumentação enumerados acima.

Outro fato ainda mais preocupante está relacionado com o ensino da produção de textos argumentativos orais. As práticas envolvendo essa modalidade de uso da língua, quando são contempladas, carecem de princípios teóricometodológicos que possibilitem uma prática de ensino consistente.

Castilho (2000) apresenta uma proposta para o ensino de língua falada na qual esta deixa de ser sinônimo de caos e permissividade no uso da língua para se tornar um objeto científico. Ele apresenta dois objetivos para o estudo da modalidade:

i. fazer uma reflexão de caráter mais social, por exemplo, como se processa a alternância de turnos em uma cultura particular; 
ii. analisar a forma como o falante organizou seu texto, ou como estrutura a sentença.

O que se pode concluir a partir desses objetivos é que a língua falada é extraída de seu contexto sócio-histórico e político, isolada de modo que apenas suas características formais sejam estudadas. O contexto, nesse caso, só é utilizado para auxiliar na explicação de fenômenos para os quais o sistema linguístico em sua imanência não é suficiente.

Com o objetivo declarado de dar tratamento científico aos fenômenos linguísticos, o que uma proposta como essa faz, na realidade, é promover uma substituição de cunho epistemológico: perdem espaço pressupostos da filosofia e da literatura, que definiram a configuração da gramática tradicional, e em seu lugar são colocados os postulados do cientificismo positivista.

Trabalhos como o de Marcuschi (2001) e Cavalcante \& Melo (2006), embora abordem a oralidade numa perspectiva didática, ressaltam apenas seus aspectos formais, ignorando a sua relação com a argumentatividade.

Diante das limitações apresentadas pelos modelos aqui expostos, cabe a questão: é possível um ensino que conceba a argumentação em sua complexidade e, portanto, capaz de promover a articulação entre discurso, subjetividade, argumentação e produção/recepção de textos no interior das práticas sociais?

Neste trabalho, parto do pressuposto de que a perspectiva monodisciplinar de estudo da argumentação, apesar de coerente com a racionalidade científica moderna, marcada, sobretudo, pela fragmentação do saber e da hiperespecialização (JAPIASSU, 2006), mostra-se bastante limitada para fundamentar práticas de ensino voltadas para o desenvolvimento de competências discursivas ligadas à leitura e à produção de textos argumentativos orais e escritos. Por essa razão, tenho como objetivo apresentar elementos necessários para uma abordagem transdisciplinar de estudo da argumentação, tendo em vista sua aplicação ao processo de ensino-aprendizagem.

\section{DISCURSO E ENSINO: LIMITES DAS ABORDAGENS DISCIPLINARES}

De acordo com Deacon e Parker (2002), a educação no mundo moderno está sendo denunciada como um dos últimos e minados baluartes de uma época cujos ídolos - a razão, o progresso e o sujeito autônomo - têm sido irreparavelmente maculados por guerras mundiais, totalitarismo, pobreza e fome em massa, destruição ambiental, e cujos próprios avanços científicos e sucessos produtivos estão inextricavelmente entrelaçados com dominação de formações naturais e sociais. A modernidade pode ser caracterizada como: um agrupamento dinâmico de desenvolvimentos conceituais, práticos e institucionais, associados com a tradição iluminista do pensamento secular, materialista, racionalista e individualista; a separação formal entre o privado e o público; a emergência de um sistema mundial de nações-estados; uma ordem econômica expansionista, baseada na propriedade privada; o industrialismo e, por último, mas não menos importante, o crescimento 
de imensos sistemas burocráticos de organização social e regulação, tal como a escola.

Hall (2005) salienta que a época moderna fez surgir uma forma nova e decisiva de individualismo, no centro do qual se erigiu uma nova concepção de sujeito individual e sua identidade. As transformações associadas à modernidade, ocorridas entre o Humanismo Renascentista do século XVI e o Iluminismo do século XVIII, libertaram os homens de seus apoios estáveis nas tradições e nas estruturas. Em sua genealogia do sujeito moderno, Hall acrescenta que, à medida que as sociedades modernas se tornavam mais complexas, elas adquiriam uma forma mais coletiva e social. As teorias clássicas liberais de governo, baseadas nos direitos e consentimento individuais, foram obrigadas a dar conta das estruturas do estado-nação e das grandes massas que fazem uma democracia moderna.

Ainda de acordo com Hall, outro aspecto problematizador da questão da identidade está relacionado ao caráter da mudança na modernidade tardia; mais especificamente ao processo de mudança conhecido como globalização e seu impacto sobre a identidade. Ele defende que esse processo está fragmentando e deslocando as identidades culturais de classe, sexualidade, etnia, raça e racionalidade. Se antes estas identidades eram sólidas localizações, nas quais os indivíduos se encaixavam socialmente, hoje elas se encontram com fronteiras menos definidas que provocam no sujeito uma crise de identidade.

Por outro lado, Bauman (1999) descreve a sociedade pós-moderna como uma sociedade de consumo. Suas análises mostram que essa sociedade tem pouca necessidade de mão de obra industrial em massa e que, por conta disso, precisa engajar seus membros pela condição de consumidores. A maneira como a sociedade atual molda seus membros é ditada primeiro pelo dever de desempenhar o papel de consumidor. A norma que nossa sociedade coloca para seus membros é a da capacidade e vontade de desempenhar esse papel. Jameson (2004) analisa a nova posição que a cultura, agora totalmente imersa na lógica da mercadoria, assume nessa sociedade e Yúdice (2004) defende que os administradores de recursos globais "descobriram a cultura" e referiram-se às noções de manutenção cultural e investimento cultural, fazendo chegar ao senso comum que, o investimento (sensível ao gênero e raça) em cultura fortalecerá a fibra da sociedade civil, que, por sua vez, serve de hospedeiro ideal para o desenvolvimento político e econômico.

É esse breve quadro, problematizador da noção de cidadania, que constitui o mundo da vida com o qual o estudante vai se deparar e com o qual deve aprender a lidar. É com esse mundo que o ensino de linguagem deve estar sintonizado. Saber como funcionam os complexos mecanismos sociais que moldam a forma como construímos nossas representações sociais pode nos ajudar a combater o que vemos de impróprio, perigoso ou ofensivo à nossa moralidade. Tal como Bauman (2000), penso que, com o conhecimento do funcionamento da sociedade, o sujeito terá, pelo menos, alguma chance de exercer sua liberdade. O modelo teórico que apresentarei neste trabalho pretende, a partir do momento em que busca promover a articulação entre discurso, subjetividade, argumentação e produção de textos no interior das práticas sociais, contribuir para a elaboração de uma nova base para a pesquisa e para um ensino de linguagem capaz de viabilizar as possibilidades de exercício da liberdade. 
Quando se pensa em propostas de intervenção teórica no ensino de linguagem, acredito que, pelo menos, dois aspectos devem ser considerados, sob pena de serem ineficazes:

i. os objetivos do ensino, ou seja, para que a linguagem deve ser ensinada;

ii. as concepções de sujeito, linguagem e mundo subjacentes aos construtos teóricos que se pretendem transpor para o ensino.

Esses fatores funcionarão como delimitadores de fronteiras, uma vez que, a partir deles, serão definidos os conteúdos que serão incluídos ou excluídos da disciplina. Por outro lado, não se pode esquecer de que cada disciplina que compõe o currículo já está subordinada aos pressupostos ideológicos que fundamentam a estruturação deste como um todo. Isto implica reconhecer que, mais do que uma simples tentativa de intervenção teórica, qualquer proposta de modificação da forma de uma disciplina deverá, inexoravelmente, estar impregnada pelo comprometimento político do pesquisador e/ou do professor.

Silva (2005) define o currículo como um documento de identidade. Como tal, não pode ser concebido simplesmente como um instrumento responsável pela seleção de saberes que o estudante deve desenvolver ao longo de sua trajetória escolar, mas, sobretudo, como um documento que vai definir formas de ser e estar no mundo. Visto dessa forma, o currículo torna-se um instrumento de poder, que vai contribuir para sedimentar concepções de mundo, cultura, linguagem, identidade, trabalho, relações sociais, dentre outras. Esses aspectos não podem ser ignorados por aqueles que pensam em redefinir os contornos de uma disciplina.

Os gêneros textuais são produzidos no interior de práticas discursivas, que, por sua vez, se inscrevem no âmbito das práticas sociais. Como qualquer prática social, as práticas de linguagem são determinadas e restringidas pelo social e, ao mesmo tempo, produzem efeitos sobre ele, contribuindo para transformá-lo. Assim, a linguagem não é apenas um reflexo das estruturas sociais, mas um de seus componentes intrínsecos. Maingueneau (1984) fala da prática discursiva quando se trata de apreender uma formação discursiva como inseparável das comunidades discursivas que a produzem e a difundem: a formação discursiva é então pensada como conteúdo, como modo de organização dos homens e como rede específica de circulação dos enunciados.

A historicidade do discurso também foi considerada nas postulações de Bakhtin (2003) acerca do enunciado. Ele afirma que todo enunciado é um elo na cadeia da comunicação discursiva, é a posição ativa do falante nesse ou naquele campo do objeto e do sentido. Sendo assim, cada enunciado se caracteriza, antes de tudo, por um determinado conteúdo semântico-objetal. Por conseguinte, a escolha dos meios linguísticos e dos gêneros de discurso seriam determinadas pela ideia do sujeito de discurso centrada no objeto e no sentido.

As práticas discursivas também funcionam como mecanismos de coerção. Para Foucault (2004), trata-se de um conjunto de regras anônimas, históricas, sempre determinadas no tempo e no espaço, que definem em uma época dada e para uma área social, econômica, geográfica ou linguística dada, as condições de exercício da função enunciativa. Foucault põe em primeiro plano a historicidade 
radical do discurso e as condições institucionais de legitimação da enunciação. Foucault (1996, p. 7) concebe a inscrição do sujeito na ordem do discurso como uma permissão institucional:

[...] a instituição responde: você não tem por que temer começar; estamos todos aí para lhe mostrar que o discurso está na ordem das leis; que há muito tempo se cuida de sua aparição, que lhe foi preparado um lugar que o honra mas o desarma; e que, se lhe ocorre ter algum poder, é de nós, só de nós, que ele lhe advém.

Logo, em toda sociedade, "a produção do discurso seria, ao mesmo tempo, controlada, selecionada, organizada e redistribuída por um certo número de procedimentos que têm por função conjurar seus poderes e perigos, dominar seu acontecimento aleatório [...]" (FOUCAULT, 1996, p. 8-9).

As teorizações de Foucault foram criticadas por nomes como Hall (2003) e de Certeau (1994), que, embora reconhecessem sua contribuição para as lutas revolucionárias, acreditavam que elas deixam inapreensíveis os pontos de resistência e as bases para mudanças sociais. Entendo que toda mudança começa com o conhecimento profundo que os agentes têm daquilo que precisa ser mudado. Nisso reside a importância das investigações foucaultianas.

Hoje, em virtude do desenvolvimento da pragmática, teorias da enunciação e da etnometodologia, por um lado, e graças ao impulso das teorias da ação em sociologia, por outro, tornou-se comum pensar a linguagem como uma forma de ação sobre o mundo: ação sobre si, sobre outrem e sobre as situações e não apenas como um instrumento de comunicação ou como uma representação do mundo. Isso nos leva a conceber a linguagem como prática social entre interlocutores situados sócio, histórica e culturalmente, ao mesmo tempo em que são atravessados por relações de poder.

Nesse contexto, a linguagem reveste-se de grande importância, dado que não vai mais ser concebida como simples instrumento de comunicação, mas também como força capaz de constituir ações, comportamentos, jogos de verdade, entendimento, legitimação, luta, resistência, contradiscursos. Conforme aponta Araújo (2004, p. 263-264):

\begin{abstract}
Não há um aspecto isolado da linguagem predestinado a cumprir uma única tarefa, com exceção das demais, sejam as relações de cunho estrutural, sintagmáticas e paradigmáticas, sejam as sentenças dotadas de significação e referência, sejam os atos de fala situados. É preciso ir do signo até o discurso, quer dizer, mostrar a importância decisiva do fator discursivo, que o significado de um signo ou de um enunciado depende do uso, que o usuário age pela linguagem e que é pela linguagem que o mundo se torna significativo, podendo ser modificado, conhecido, utilizado, contatado.
\end{abstract}

Partindo de uma concepção de linguagem como prática sociocultural e política, entendo ser necessário, tal como propôs de Certeau (1994), que acreditava ser possível depreender as regras e as formalidades subjacentes às multiformes e 
fragmentárias práticas populares de resistência às culturas difundidas e impostas pela elite, depreender das práticas de linguagem imbuídas, direta ou indiretamente do objetivo de persuadir, as formalidades da argumentação. Feita essa tarefa, será possível construir um dispositivo ao mesmo tempo analítico e produtivo de textos argumentativos. Analítico porque permitiria a identificação e o julgamento dos argumentos próprios e alheios; produtivo, porque permitiria a seleção, a organização e o uso dos argumentos, de acordo com a intenção comunicativa do locutor nos mais variados contextos de interação social. Tal dispositivo consistiria num esquema geral da argumentatividade, não fechado, mas nem por isso totalmente aberto, composto por espaços dotados de propriedades restritivas responsáveis por definir os conteúdos argumentativos que podem ocupá-los. Esses conteúdos, logicamente, não seriam os mesmos para todos os momentos históricos ou para todos os grupos sociais indistintamente, embora, dependendo da situação possa haver, como frequentemente ocorre, deslocamentos de conteúdos pertencentes a períodos ou grupos sociais diferentes daqueles nos quais os interlocutores se acham inscritos em dada situação comunicativa.

\section{DISCURSO E ARGUMENTAÇÃO: POR UM ENSINO TRANSDISCIPLINAR}

$\mathrm{Na}$ história dos estudos da linguagem, pode-se afirmar que a retórica foi a única disciplina que conseguiu promover, no ensino de produção de textos, a articulação entre discurso, subjetividade, argumentação e produção de textos no interior das práticas sociais. Isso, evidentemente, se deu num período em que suas teorizações estavam em consonância com as exigências da sociedade. Considerando a persuasão como uma maneira de pensar investida numa maneira de agir, uma arte de combinar indissociável de uma arte de utilizar, fez aquilo que as proposições didáticas atuais, baseadas na visão fragmentária das teorias científicas contemporâneas da linguagem, se esmeram para fazer, mas sem sucesso: uma prática de ensino de produção de textos que concebe a relação teoria-prática de forma articulada e globalizante.

Como se sabe, a retórica nasceu na Grécia, no seio de homens que cultivavam como um de seus prazeres mais refinados a oratória, o dom da eloquência. $\mathrm{O}$ aparecimento da polis, por volta dos séculos VIII e VII a.C., com seu sistema específico de governo, é um dos acontecimentos decisivos da história do pensamento grego. A existência de uma ou mais assembleias e dos conselhos, com magistrados escolhidos entre personalidades elegíveis, fazia com as decisões governamentais fossem coletivas, votadas depois da discussão delas nesses conselhos e assembleias, com participação obrigatória para toda a comunidade, que tinha ali direito soberano (excluídos os escravos, as mulheres e os metecos estrangeiros residentes). Considerando-se, ainda, que não havia separação muito rígida entre o que pertencia à esfera do legislativo e do judiciário, temos que na polis era fundamental a habilidade discursiva de cada um para defender publicamente seus direitos e convicções. Nesse contexto, não é de se estranhar que houvesse uma extraordinária valorização da palavra em relação a todos os outros instrumentos de 
poder. Ela transforma-se no instrumento político por excelência, a chave de toda a autoridade nos Estados, o meio de comando e de domínio sobre os outros. Todas as questões de interesse geral eram submetidas à arte oratória e teriam de ser resolvidas no final de um debate; portanto, era necessário que elas pudessem ser formuladas em discurso, que entrassem no molde de demonstrações antitéticas, de argumentações contrárias. Entre a política e o logos havia, pois, uma ligação estreita, um laço recíproco. No essencial, a arte política era, e continua sendo, manipulação da linguagem.

É entre os sofistas que essa nova organização de valores melhor se aclimata, ou, antes, são eles que lhe dão impulso. Ao contrapor à antiga filosofia cosmológica, centrada nas indagações sobre os princípios de ordem natural, a ideia de que os problemas do homem são mais significativos e mais urgentes do que os da natureza, os sofistas chamam a atenção para o mundo fenomênico, para as contingências do dia a dia e para a irremediável subjetividade de nossos julgamentos e de nosso modo de conhecer a realidade, onde não há verdade absoluta. $\mathrm{Na}$ Atenas de Péricles, no esplendor da vida política e das liberdades democráticas, os sofistas abandonam o ideal especulativo e se propõem uma finalidade prático-educativa, tornando-se uma espécie de "mestres de virtudes", sendo os primeiros que dão aulas mediante pagamento, no intuito de preparar o homem para a vida política. Na esteira aberta pelos sofistas, militam Sócrates, Platão e Aristóteles, os quais imprimem à retórica sua vertente filosófica, que deitará raízes entre os Padres da Igreja e entre os pensadores subsequentes.

A retórica de Aristóteles, graças à sua preocupação de conceituar e distribuir por partes cada passo e todos os mecanismos que interagem na organização da arte da eloquência, tornou-se para a posteridade o manual preceptivo por excelência da melhor maneira de compor o discurso. É daí que se começa sempre e, mesmo que se recorra à fonte preciosa da oratória ciceroniana ou à difundida Epístola de Horácio, é a Aristóteles que se retorna, considerado o pai da retórica. A retórica do estagirita concentra a força de seu raciocínio no item das provas e da demonstração. Por isso, logo no capítulo I do Livro I Aristóteles (1959, p. 19-20) a define:

Sendo manifesto que o método hábil se estriba em provas; que a prova é uma demonstração - pois que a nossa confiança é tanto mais firme quanto mais convencidos estivermos de ter obtido uma demonstração -; atendendo a que a demonstração da Retórica é o entimema; que este fornece, em resumo, a convicção mais decisiva; assente que o entimema é uma espécie de silogismo e que a Dialética, tomada em conjunto ou numa de suas partes, tem por missão tratar indiferentemente de toda a sorte de silogismos, resulta que todo aquele que melhor souber aprofundar as premissas e a marcha do silogismo, será, por isso mesmo, mais apto para manejar o entimema, desde que possua igualmente o conhecimento dos objetos a que os entimemas se referem e das diferenças que os distinguem dos silogismos lógicos. Com efeito, a distinção do verdadeiro e do verossímil depende da mesma faculdade.

Portanto, a retórica, ao "aprofundar as premissas e a marcha do silogismo", ensina um conhecimento muito peculiar do objeto, já que é preciso ver em cada caso, teoricamente, o que pode ser capaz de gerar a persuasão. Daí que suas regras 
servem não só a um gênero próprio e determinado, mas atuam como substrato de qualquer método que vise a convencer.

As provas que o próprio discurso fornece - basta saber inventá-las - são de três espécies: ou residem no caráter moral do orador - o ethos - (indispensável, principalmente quando não há possibilidade de se obter certeza nas questões tratadas); ou nas disposições que se criam nos ouvintes - o pathos - (quando se consegue levá-los a sentir uma paixão); ou naquilo que o discurso em si parece mostrar, na construção do raciocínio - o logos - (neste caso, a verdade ou um simulacro dela). Aristóteles reconhece que essa tripartição coloca a retórica como limítrofe da dialética e da política.

É preciso adequar essas normas aos três gêneros da retórica - subdivisão que embasará todos os tratados de eloquência posteriores: o gênero deliberativo, quando se aconselha ou desaconselha para que se decida sobre questões de interesse particular ou público; o gênero judiciário, que comporta sempre uma acusação e uma defesa; e o gênero epidíctico, que se volta para o elogio e a censura. Em outras palavras, trata-se do discurso político, do discurso forense e do discurso de ocasião, a serem pronunciados, respectivamente, numa assembleia, num tribunal ou em situações comemorativas. Nessas concepções distributivas das funções da oratória, está uma das contribuições fundamentais de Aristóteles para a permanência dos conceitos retóricos: ele acaba propondo, indiretamente, o ouvinte, o público, o leitor, o espectador, o enunciatário, o narratário, o co-enunciador etc., como o verdadeiro juiz da eficácia do discurso, fazendo com que toda a teoria convirja para a argumentação. Por isso, o Livro II da Arte retórica gira em torno de uma espécie de teoria das paixões que, dentre outros conceitos, estabelece a distinção entre ethos e pathos: no primeiro caso, a persuasão decorre de qualidades centradas na personalidade do orador; no segundo, no público ouvinte.

O Livro III da Arte retórica versa sobre a elocução e compõe, com o estudo das paixões, o destaque da obra - por oferecer subsídios à estilística, onde a linguística enunciativa e a pragmática têm bebido algumas bases das formulações teóricas contemporâneas. Desenvolve-se segundo o preceito da "justa medida", caro aos gregos:

O estilo terá a conveniência desejada, se exprimir as paixões e os caracteres e se estiver intimamente relacionado com o assunto. Esta relação existe quando não se tratam de modo rasteiros assuntos importantes, nem enfaticamente assuntos vulgares, quando não se enfeita de ornamentos uma palavra ordinária. (ARISTÓTELES, 1959, p. 203)

Tão minuciosos são os desdobramentos dessa proposição, que impõem a divisão dos discursos em partes, cada uma contendo seu estilo próprio: o exórdio, a exposição, a prova e o epílogo. Cabe aqui o elenco das figuras de linguagem que, retomadas pelos romanos, darão um tom mais pragmático à retórica latina, além de distingui-la da tradição platônica e aristotélica.

No entanto, o surgimento de um novo paradigma discursivo, instituído pela ciência moderna, que aspirava a alcançar a natureza das coisas, excluirá do enunciado as pessoas do enunciador e do enunciatário e vai referendar os 
mecanismos veredictórios do discurso na impessoalidade de um sujeito que diz "sabe-se", "é evidente", "concede-se". O apagamento, no enunciado, do enunciador, e seu saber, por meio de construções impessoais como as citadas e, ainda, por processos de referência como "viu-se que" ou "ver-se-á que" tem por objetivo produzir o sujeito impessoal, que não mimetiza papel social algum, antes demarca uma posição que, por isso mesmo, indetermina o enunciador do discurso. Essas concepções de produção discursiva e de subjetividade é que se encontram na base das orientações para a produção de textos dissertativos que os nossos docentes propõem aos estudantes.

É principalmente por meio dessa pragmática, neutralizadora das distinções hierárquicas entre o sujeito produtor e o leitor, que se busca excluir do discurso da ciência moderna a discursividade retórica, uma vez que, eliminada a pessoa do enunciador, elimina-se também a do enunciatário, alvo do fazer persuasivo.

Com o advento do Romantismo, o exercício da imitação das autoridades do passado será repudiado em prol da originalidade, que só o homem de gênio, abrilhantado pela inspiração pode alcançar. Isso dá origem às desculpas dadas pelos estudantes quando não conseguem iniciar sua produção textual: "não estou inspirado hoje".

Nesse regime discursivo, a autoria é o título de propriedade que reconhece a subjetividade como causa da obra. O discurso não mais se reporta a um paradigma genérico, consagrado por uma autoridade pretérita e conservado pela imitação, mas encontra sua identidade no sujeito que, por meio dele expressa sua singularidade. Um dos grandes prejuízos que esse novo regime acarreta para o ensino de produção de textos é a perda de critérios para se avaliar um texto. Como saber se um texto está bem construído? Como dizer que ele não está bom, se expressa a opinião do autor? Como julgar a opinião do autor? Conforme afirmam Faria et. al., na introdução que fazem à Retórica a Herênio (CÍCERO, 2005, p. 32):

Concebido como disposição inata no artista, pela qual a natureza dá regra à arte, o gênio não pode, ele mesmo, prescrever ou ensinar e, assim, instrumentalizar outros para criar produtos equivalentes aos seus. A regra que ele estabelece não é formular, mas algo que só pode ser abstraído do produto artístico e que só servirá ao talento de outros homens, se a natureza os tiver provido de semelhante proporção de faculdades mentais. Assim tomadas as regras da arte como naturais e expressas pelo gênio, a preeminência de um código cultural como a retórica não será mais possível.

À medida que perde sua centralidade, a retórica vai sendo reduzida a uma de suas partes: a elocução. Esta é reproposta, no âmbito do romantismo, como inventário de recursos expressivos, que já não se associam à matéria especificada pela conveniência de cada gênero discursivo, mas se empregam para obter um uso desviante da linguagem, adequado à exigência de originalidade que orienta a produção literária após o século XVIII. Com a preponderância da elocução, o adjetivo "retórico" passa a designar, pejorativamente, o discurso cuja falta de substância estaria encoberta pela ênfase na expressão. 
Mesmo tendo deixado de ordenar o discurso teórico e prático, a retórica persistiu de forma residual ao longo dos séculos em que esteve à margem do discurso. O saber que dominava, absoluta, até a modernidade, está hoje fragmentado nos currículos acadêmicos das várias ciências humanas. O retorno contemporâneo da retórica, agora problematizada nos quadros dessas disciplinas, é, por isso mesmo, também fragmentário. Não funciona como fator de unificação das várias práticas discursivas nas quais ressurge, que continuam a distinguir-se por seus objetos e corpos teóricos específicos. Reboul (2004), contudo, assinala que, se a retórica perdeu o nome, nem por isso morreu. Não só sobrevive no ensino da literatura, nos discursos jurídicos e políticos, como também vai renovar-se com a comunicação de massa, própria do século XX.

Finalmente, a partir dos anos 60 aparece na Europa uma nova retórica, a de Chaïm Perelman e Lucie Olbrechts-Tyteca, cujo livro mais importante é o Tratado da argumentação, a Nova Retórica. Essa obra, que se insere na tradição retórica de Aristóteles, é realmente uma teoria do discurso persuasivo. Seus autores partiram de um problema, não linguístico nem literário, mas filosófico: como fundamentar os juízos de valor? O que nos permite afirmar que isto é justo ou que aquilo não é belo? Buscaram, pois, a lógica do valor, paralela à da ciência, e acabaram por encontrá-la na antiga retórica, completada pela dialética. A grande redescoberta desse Tratado é que, entre a demonstração científica e a arbitrária das crenças, há uma lógica do verossímil, a que dão o nome de argumentação, vinculando-a à antiga retórica.

No essencial, esse livro é um estudo dos diversos tipos de argumentos; dedica um pequeno espaço para as figuras, porém reduzindo-as a condensados de argumentos. Em suma, uma retórica centrada na invenção e não na elocução. Portanto, também incompleta. De fato, se o Tratado descreve maravilhosamente as estratégias da argumentação, deixa de reconhecer os aspectos afetivos da retórica, essenciais à persuasão.

Apesar disso, entendemos que as postulações de Perelman-Tyteca (2005), aliadas a elementos da retórica antiga e das teorias linguísticas contemporâneas, contribuirão para a construção do dispositivo analítico-produtivo que vai compor o esquema geral da argumentatividade pretendido por este trabalho.

Perelman-Tyteca estabelecem que não há argumentação possível sem algum acordo prévio entre o orador e seu auditório. Este acordo é obtido por meio de premissas comuns, implícitas ou explícitas, que assumem a forma de fatos, verdades e presunções. O Tratado distingue quatro categorias de argumentos:

1) Os quase lógicos. Cada um dos argumentos quase lógicos é aparentado com um princípio lógico, como a identidade ou a transitividade; e, assim como eles, são a priori, no sentido de que não fazem apelo à experiência.

2) Os que se fundam na estrutura do real. Não se apoiam na lógica, mas na experiência, nos elos reconhecidos entre as coisas. Aqui, argumentar não é implicar, mas explicar.

3) Os que fundam a estrutura do real. São empíricos, mas não se apoiam na estrutura do real: criam-na; ou pelo menos a completam, fazendo que entre as coisas apareçam nexos antes não vistos, não suspeitados. 
4) Os que dissociam uma noção. Os argumentos do quarto tipo consistem em dissociar noções em pares hierarquizados, como aparência/realidade, meio/fim, letra/espírito etc. Distinguem-se assim de todos os outros argumentos, que associam as noções.

Apesar de não tratar da argumentação de maneira explícita, a teoria bakhtiniana dos gêneros do discurso constitui uma referência fundamental quando se trata de pensar a noção de gêneros para além da classificação aristotélica dos gêneros retóricos e literários. Em Estética da criação verbal, Bakhtin (2003) dedicou dois capítulos ao tratamento do tema, Os gêneros do discurso e O problema do texto na linguistica, na filologia e em outras ciências humanas, nos quais apresentou os fundamentos de sua teoria e elencou um conjunto de peculiaridades dos enunciados que será muito útil para este trabalho, na medida em que contribuirá para a elaboração do que se poderia chamar de macroestrutura orgânica dos gêneros do discurso. Ele definiu três aspectos constitutivos do enunciado como unidade de comunicação discursiva:

i) A alternância dos sujeitos do discurso. O enunciado é um elo na cadeia de comunicação discursiva e está disposto para a resposta do outro, para a sua compreensão responsiva, que pode assumir diferentes formas; ele determina as posições responsivas dos outros nas complexas condições de sua produção.

ii) A conclusibilidade específica do enunciado. Trata-se de uma espécie de aspecto interno da alternância dos sujeitos no discurso, que só pode ocorrer precisamente porque o falante disse tudo o que quis dizer em dado momento sob dadas condições. Essa inteireza é determinada por três elementos intimamente ligados no todo orgânico do enunciado:

a) Exauribilidade do objeto e do sentido. O objeto é objetivamente inexaurível, mas, ao tornar-se tema do enunciado, ele ganha uma relativa conclusibilidade em determinadas condições, em determinados objetivos colocados pelo autor, ou seja, já no âmbito de uma ideia definida do autor.

b) Projeto de discurso do autor. Em cada enunciado abrangemos, interpretamos, sentimos a intenção discursiva do autor, que determina o todo do enunciado, o seu volume e as suas fronteiras. Essa ideia - momento subjetivo do enunciado - se combina em uma unidade indissolúvel com seu aspecto semântico-objetivo (temático), restringindo este último, vinculando-o a uma situação concreta de comunicação, com todas as suas circunstâncias individuais.

c) As formas estáveis de gênero do enunciado. A intenção discursiva do autor se realiza na escolha de um certo gênero do discurso. Essa escolha é determinada pela 
especificidade de um dado campo de comunicação discursiva, por considerações temáticas, pela situação em que se dá a comunicação, pela composição pessoal e social de seus participantes etc.

iii) O estilo do autor. A oração como unidade da língua não tem autor e só funcionando como enunciado pleno ela se torna expressão da posição do falante individual em uma situação concreta. Todo enunciado é a posição ativa do falante em algum campo do objeto e do sentido. Assim, escolha dos meios linguísticos e dos gêneros de discurso é determinada, antes de tudo, pelas ideias do autor centradas no objeto e no sentido. Isso determina as peculiaridades estilístico-composicionais do enunciado, que devem levar em conta, ainda, a relação do enunciado com o próprio autor e com outros participantes da comunicação.

Como vimos, apesar de sua fragmentação, resíduos da retórica estão presentes em várias disciplinas. No entanto, a produção de textos, que era o seu principal objetivo, na contemporaneidade, não tem lançado mão de suas contribuições. Afirmamos, ainda, que a retórica antiga conseguia operar a produção dos gêneros retóricos sem a dicotomia teoria/prática, algo que as hodiernas teorias científicas da linguagem não conseguem. Além disso, apontamos insuficiências de ordem teórica que impossibilitam a essas disciplinas uma adequada abordagem da complexidade que envolve a relação entre linguagem e sociedade.

Essas considerações são importantes porque vão tocar em alguns aspectos muito importantes, diretamente ligados aos objetivos deste texto: dado que as perspectivas monodisciplinares da linguística se mostram limitadas para abordar o tema da argumentação em sua complexidade, sobretudo em função de seu compromisso com a produção de conhecimentos de base em que prevalece a fragmentação do saber, tal tarefa só poderia ser levada a termo por uma linguística concebida como ciência aplicada crítica, no sentido amplo do termo, comprometida com os seguintes princípios:

i) Expansão dos dados que estuda, das disciplinas-fonte e das metodologias, em função da necessidade de entendimento dos problemas sociais de comunicação em contextos específicos (o seu objeto abrangente) que procura resolver (o seu objetivo abrangente) (KLEIMAN, 2004).

ii) Compromisso com a utilidade social da pesquisa, ou seja, propõe-se a contribuir para resolver problemas da vida social (KLEIMAN, op. cit.).

iii) Inter e transdisciplinaridade. O linguista aplicado, partindo de um problema com o qual as pessoas se deparam ao usar a linguagem na prática social e em um contexto de ação, procura subsídios em várias disciplinas que possam iluminar teoricamente a questão em jogo (MOITA LOPES, 2004).

No entanto, não podemos ignorar que, conforme aponta Giddens, não são raros os casos em que a teoria precede a observação: "Hoje, dada maior consciência de que a observação sensorial é permeada por categorias teóricas, o pensamento filosófico em suas correntes principais afastou-se decididamente do empirismo" 
(GIDDENS, 1991, 55). Considerando que o linguista aplicado empreende suas atividades investigativas munido de pressupostos teóricos formulados, principalmente, por disciplinas da linguística, como a linguística textual, a sociolinguística, teorias enunciativas, teorias dos gêneros textuais, teorias de ensino e aprendizagem etc., e levando em conta as insuficiências das abordagens monodisciplinares, entendo que a linguística aplicada terá muito a ganhar com uma produção teórica de cunho aplicado, marcadamente transdisciplinar. Esse tipo de produção teórica não teria nenhuma relação com a abordagem imanente do objeto, tal como faz a linguística básica. Antes, seria construída visando a resolução de problemas específicos.

Defendo, portanto, que a estrutura formal da argumentação deve ser depreendida das práticas de linguagem que engendram os gêneros textuais imbuídos, direta ou indiretamente, do objetivo de persuadir. Para isso, é necessário que se percorram dois caminhos. O primeiro deles consiste na construção do aparato teórico-metodológico, a partir da apropriação - no sentido que Pêcheux (1998) confere ao termo - de construtos teóricos da retórica antiga, da nova retórica e de teorias linguísticas como a pragmática, a linguística textual, a semântica argumentativa, teorias dos gêneros textuais, a análise de discurso, teorias enunciativas, a análise da conversação, da sociologia, dos estudos culturais, da filosofia, da filosofia da linguagem e outras, de acordo com os objetivos do processo de ensino-aprendizagem. $O$ segundo caminho consiste na construção de um dispositivo teórico metodológico capaz de fundamentar práticas de análise e produção de textos argumentativos, concebidos como objetos de extrema complexidade. A Figura 1 apresenta uma síntese desse dispositivo.

Figura 1 - Dispositivo de análise/produção de textos argumentativos

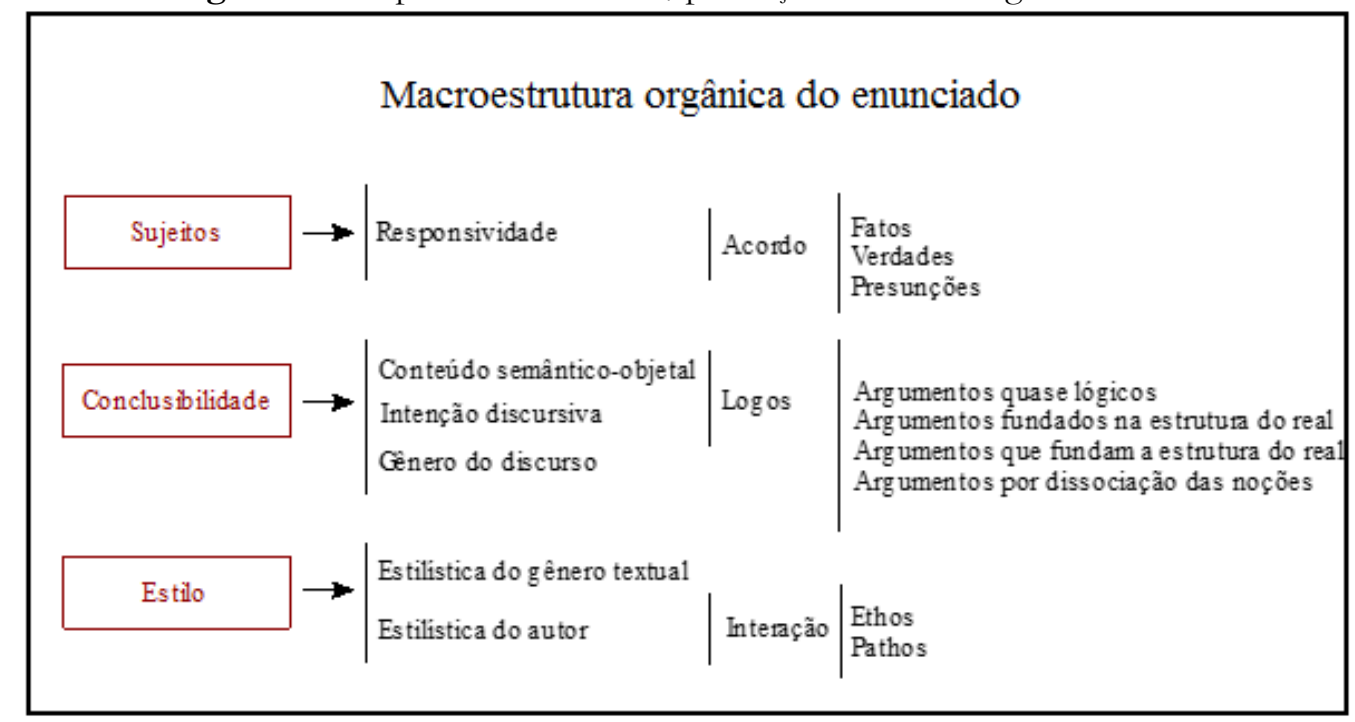

No contexto de uma política educacional voltada para a formação política e cidadã, o ensino da argumentação deve ser situado no conjunto das práticas discursivas em que se situam os gêneros através dos quais os sujeitos são interpelados e aos quais devem desenvolver atitudes responsivas, tendo em vista a 
compreensão e como a construção dos argumentos afetam os processos sociais ligados à produção de identidades e identificações.

\section{CONSIDERAÇÕES FINAIS}

No início deste texto, coloquei a problemática do ensino da argumentação, situando-a entre dois polos: o das práticas tradicionais institucionalizadas e o das abordagens monodisciplinares das diversas teorias linguísticas alinhadas ao modelo de racionalidade da ciência moderna.

O contexto sociopolítico e econômico da modernidade tardia ou da pósmodernidade confere à linguagem, em geral, e à argumentação, em particular, extrema relevância no processo de socialização, o que aumenta a responsabilidade da escola quanto à formação das novas gerações.

O dispositivo de análise e produção de textos argumentativos aqui proposto constitui-se pela confluência de contribuições disciplinares diversas, mas não se pode concluir que sua representação final pode ser concebida como o resultado da soma de todas elas. Se assim fosse, seríamos forçados a admitir que a abordagem multidisciplinar, através da qual o que falta em uma disciplina é preenchido pelos conteúdos de outras, confere à ciência um caráter totalizante. A ciência, apesar das inúmeras contribuições que possa dar ao estudo da argumentação, mostra-se, em função de suas características internas, limitada para o estudo da argumentação em sua complexidade e, por conseguinte, para subsidiar suas práticas de ensino. Por essa razão, considero a abordagem transdisciplinar como mais pertinente para orientar as práticas de estudo da argumentação comprometidas com as finalidades pedagógicas. Tal perspectiva reconhece os limites da ciência e, por isso, permite que se considere, ao mesmo tempo, o que está entre as disciplinas e o que está aquém e além delas.

O dispositivo tem como seus grandes eixos construtos conceituais da teoria bakhtiniana do enunciado, da retórica clássica e da nova retórica. Contudo, a operacionalização do modelo impõe que se recorra a contribuições de diversas outras disciplinas e a outros saberes que não figuram como objetos da ciência. $\mathrm{O}$ mapeamento exato dos diversos elementos que compõem todos os grandes eixos ainda está por ser feito.

\section{REFERÊNCIAS}

ADAM. J. M. A linguística textual: introdução à análise textual dos discursos. Trad. Maria das Graças Soares Rodrigues et. al. São Paulo: Cortez: 2008.

ANSCOMBRE, J-C.; DUCROT, O. L'argumentation dans la langue. 3. ed. Bruxelles, Pierre Mardaga, 1997.

ARAÚJO, I. L. Do signo ao discurso: introdução à filosofia da linguagem. São Paulo: Parábola Editorial, 2004. 
ARISTÓTELES. Arte retórica, arte poética. Trad. Antônio Pinto de Carvalho. São Paulo: Difusão Europeia do Livro, 1959.

BAKHTIN, M. Estética da criação verbal. 4. ed. Trad. Paulo Bezerra. São Paulo: Martins Fontes, 2003.

BAUMAN, Z. Globalização: as consequências humanas. Trad. Marcus Penchel. Rio de Janeiro: Jorge Zahar Ed., 1999.

2000.

. Em busca da politica. Trad. Marcus Penchel. Rio de Janeiro: Jorge Zahar Ed.,

CASTILHO, A. T. A língua falada no ensino de português. 3. ed. São Paulo: Contexto, 2000.

CAVALCANTE, M. C. B. e MELO, C. T. V. de. Oralidade no ensino médio: em busca de uma prática. In: BUNZEN, C.; MENDONÇA, M. (Orgs.). Português no ensino médio e formação do professor. São Paulo: Parábola Editorial, 2006, p. 181-198.

CERTEAU, M. de. A invenção do cotidiano: artes de fazer. Trad. Ephraim Ferreira Alves. Petrópolis, Rio de Janeiro: Vozes, 1994.

CÍCERO. Retórica a Herênio. Trad. Ana Paula Celestino Faria e Adriana Seabra. São Paulo: Hedra, 2005.

DEACON, R.; PARKER, B. Educação como sujeição e como recusa. In: SILVA, T. T. da. (Org.). O sujeito da educação. 5. ed. Petrópolis, RJ: Vozes, 2002.

FOUCAULT, M. A ordem do discurso. 11. ed. Trad. Laura Fraga de Almeida Sampaio. São Paulo: Edições Loyola, 1996.

2004.

- Arqueologia do saber. Tradução L. F. Baeta Neves. Rio de Janeiro, Forense,

GIDDENS, A. As consequências da modernidade. Trad. Raul Fiker. São Paulo: Editora UNESP, 1991.

HALL, S. Da diáspora. Trad. Adelaine La Guardiã Resende et. al. Belo Horizonte: Editora UFMG, 2003.

. Identidade cultural na pós-modernidade. 10. ed. Trad. Tomaz Tadeu da Silva. Rio de Janeiro: DP\&A, 2005.

JAMESON, F. Pós-modernismo: a lógica cultural do capitalismo tardio. 2. ed. Trad. Maria Elisa Cevasco. São Paulo: Editora Ática, 2004. 
JAPIASSU, H. O sonho transdisciplinar e as razões da filosofia. Rio de Janeiro: Imago, 2006.

KLEIMAN, A. B. O estatuto disciplinar da linguística aplicada: o traçado de um percurso, um rumo para o debate. In: SIGNORINI, I. e CAVALCANTE, M. (Orgs.). Linguistica aplicada e transdisciplinaridade. Campinas, São Paulo: 2004.

KOCH, I. G. V. Argumentação e linguagem. 9. ed. São Paulo: Cortez, 2004. . Desvendando os segredos do texto. 5. ed. São Paulo: Cortez, 2006.

MAINGUENEAU, D. Gêneses du discours. 2. ed. Bruxelles, Pierre Mardaga, 1984.

MARCUSCHI, L. A. Da fala para a escrita: atividades de retextualização. 3. ed. São Paulo: Cortez, 2001.

. Gêneros textuais: definição e funcionalidade. In: DIONÍSIO, A. P. et al. (Orgs.) Gêneros textuais e ensino. 2. ed. Rio de janeiro: Editora Lucerna, 2002, p. 1936.

MEURER, J. L. et al. (Orgs.). Gêneros: teorias, métodos, debates. São Paulo: Parábola Editorial, 2005.

MOITA LOPES, L. P. da. A transdisciplinaridade é possível em linguística aplicada? In: SIGNORINI, I. e CAVALCANTE, M. (Orgs.). Linguística aplicada e transdisciplinaridade. Campinas, São Paulo: 2004.

PÊCHEUX. M. Semântica e discurso: uma crítica à afirmação do óbvio. Tradução Eni Pulcinelli Orlandi et al. 2. Ed. Campinas, SP: Editora da UNICAMP, 1998.

PERELMAN, Ch.; OLBRECHTS-TYTECA, L. Tratado da argumentação: a nova retórica. Trad. Maria Ermantina de Almeida Prado Galvão. São Paulo: Martins Fontes, 2005.

REBOUL, O. Introdução à retórica. Trad. Ivone Castilho Benedetti. São Paulo: Martins Fontes, 2004.

SILVA, T. T. da. Documentos de identidade: uma introdução às teorias do currículo. 2. ed. Belo Horizonte: Autêntica, 2005.

YÚDICE, George. A conveniência da cultura: usos da cultura na era global. Trad. Marie-Anne Kremer. Belo Horizonte: Editora UFMG, 2004. 